\title{
An Approach to Student-Oriented Educational Program of Medical Ethics
}

\author{
Kenji Hattori ${ }^{1}$
}

\begin{abstract}
Backgrounds \& Aims : Most medical schools have acknowledged the importance of medical ethics education. Yet the methodology for such an education has to be established.

Methods : We used an 8-item questionnaire to survey the needs and expectations of medical students with regard to their medical ethics class.

Results : One hundred and nineteen first-year students voluntarily responded to this survey. Students from two different school years gave considerably similar responses. The opinions of many students were as follows : the medical ethics class should be offered, necessary and sufficient hours for such a class would be two or four semester hours, the course should not follow the National Examination for Physicians format, sessions consisting of both lectures and discussions are desirable, and the course should start in the first grade. They felt that a clinical doctor, a philosopher interested in medicine, or a medical professional who has studied philosophy and ethics would be most appropriate as the teacher in charge. The teachers' roles anticipated were to introduce actual ethical problems in a clinical setting, to provide coordinate axes for the opinions and values of each students, and to instigate arguments.

Conclusions : The items that provide the key to a plethora of medical ethics education concerns are 1) the cooperation between clinical doctors and philosophers and ethicists, 2) the introspective discussionoriented class format, and 3) an acceptance and ensuring of divergent perspectives. (Kitakanto Med J $2002 ; 52: 99 \sim 106)$
\end{abstract}

Key Words: Medical ethics, Undergraduate class, Student-centered education, Methodology

\section{Introduction}

Over the past few years the field of medical ethics has gained recognition as an extremely important subject and, as a result, concerns over methodology have experienced a drastic increase. And yet we cannot confirm that the present educational system reflects any of this common recognition. Less than one quarter of the 80 medical schools in Japan offer separate courses dealing with medical ethics. Furthermore the concept and style of these classes varies and lacks any unity among the courses being offered at each of the schools. Serious differences still remain; the aims of the courses, total classroom hours, the number and specialties of the faculty members in charge, the thematic content, the grades for which the courses are to be offered, and the methods of instigating student participation in the classroom. In addition the standard criterion for determining questions used in the National Examination for Physicians (NEP) is now changing. These factors make it quite difficult for medical schools to have total confidence in their own programs as they continue to grope for better educational methods.

Surveys of medical ethics curriculums of medical schools all over the country have been thoroughly documented in the literature, ${ }^{1}$ as have the introductions of unique curriculums that have actually been put into practice, ${ }^{2 \sim 5}$ as well as proposals for new trials. ${ }^{6}$ Several studies have been made based upon opinion polls of medical students and/or their subjective evaluations to the courses they have taken., ${ }^{7,8}$ To our knowledge, however, there has been no study that has tried to grasp the needs and intentions of medical students. The purpose of this study is to examine these needs and intentions, and to explore possibilities

1 Department of Medical Philosophy and Ethics, Gunma University Faculty of Medicine 3-39-22 Showa, Maebashi, Gunma 371-8511, Japan

Received: January 18, $2002 \quad$ Accepted : January 30, 2002

Address : KENJI HATTORI, M.B., M.A. Department of Medical Philosophy and Ethics, Gunma University Faculty of Medicine 3-39-22 Showa, Maebashi, Gunma 371-8511, Japan 
for the development of a well-grounded curriculum dealing primarily with medical ethics.

\section{Subjects and Methods}

The survey population consisted of first-year students in a medical school who had been taking a medical ethics course for approximately three months. All subjects received an 8-item structured, anonymitytype questionnaire after one class. The students were all told that their participation in this survey was entirely voluntary and not coerced. Respondents replied to the questionnaire after agreeing to cooperate with the survey and being informed of the official announcement of the result. Data were collected in the early summer of 2000 and 2001.

We examined the subjective opinions of medical students on the following questions.
1. How much value does the medical ethics class have?

2. How much time should be spared for this subject?

3. What kind of person would be fit to teach a course on medical ethics?

4. Should the class be conscious of the National Examination for Physicians or not?

5. What is a suitable form of the class and the evaluation examination?

6 . What is expected of the class?

7. In which grade should the class be offered?

There were free entry columns in the questionnaire so that students might mention the reasons for their responses to questions. The form of questionnaire used is shown in Table 1. The ages of the students was not requested since, in some cases, age alone could be used to identify some individual respondents in such a

\section{Table 1. MEDICAL ETHICS EDUCATION SURVEY REQUEST}

A. Is a medical ethics course a necessity in a medical department curriculum?

Totally unnecessary

More necessary than not

Necessary

Definitely necessary

Reasons (

(Only for those who responded that a medical ethics course is necessary)

B. How much time should be devoted to such a course?

1 credit hour (for one term)

1 credit hour (for one year)

2 credit hours (one year course)

More credit hours are necessary.

C. What type of person would be most suited to teaching a medical ethics course? Draw a double circle (0) Around the most appropriate type and a circle $\bigcirc$ around the next most appropriate type of teacher. Medical philosopher / medical ethicist

Medical legal professional

Priest/theologian

Welfare professional

Nurse

Clinician

Medical researcher

Medical professional who has undergone a philosophical and/or a medical ethics education

Municipal activist

Other (specifically ;

Reason (

D. Do you feel that a medical ethics course should take the National Examination for Physicians (NEP) into account?

The course should concentrate on the NEP.

Much weight should be devoted to the NEP.

Little weight should be devoted to the NEP in class.

The NEP should be of no concern with regard to the content of the class.

Reason (

E. What kind of classroom activities do you feel would be most appropriate?

Primarily lectures

Primarily discussions

Both lectures and discussions (lecture $\%$, discussion $\%)$ 
F. What kind of anticipations do you have for the professor?

Draw a double circle $($ ) around the most desirable anticipation and a circle $\bigcirc$ around the next most desirable anticipation.

Introductions of actual situations in a clinical setting

Explanations of research and theoretical trends

Instigating arguments and dealing with problems

Abundant scholarship in the field of medicine and medical treatment

Abundant scholarship in the field of medical law

Abundant scholarship in the field of philosophy and ethics

Abundant scholarship in the field of medical policy

Responsive to the opinions of students

Offerings of the most appropriate moral judgments

Proper manners and etiquette for doctors

Presentation of personal opinions and experiences

Thoughts from a number of different perspectives

Reasons (

G. What kind of test do you feel could best evaluate students in the course?

NEP "yes/no" test format

Essay test

Reason (

H. What year of medical school should students take the medical ethics course? Year (

closed population.

\section{Results}

Seventy-two of the 85 first-year students (response rate, $84.7 \%$ ) in fiscal year 2000 and 47 of the 85 firstyear students (response rate, 55.3\%) in fiscal year 2001 participated in this survey. Below, the set of first-year students in fiscal year 2000 is designated as 'Student2000', and the other set as 'Student-2001'.

\section{Recognition of the importance of a medical ethics class}

In the Student-2000 group, 29 (40.3\%) considered the class to be an absolutely necessity. Forty-one $(56.9 \%)$ claimed that the course should be offered. In the Student-2001 group, figures for these same

Table 2. Necessity of medical ethics course in medical school

\begin{tabular}{lcc}
\hline & Student-2000 & Student-2001 \\
\hline Totally unnecessary & $0(0.0)$ & $1(2.1)$ \\
More necessary than not & $2(2.8)$ & $0(0.0)$ \\
Necessary & $41(56.9)$ & $27(57.5)$ \\
Definitely necessary & $29(40.3)$ & $19(40.4)$ \\
\hline
\end{tabular}

Values are $n(\%)$. responses were $19(40.4 \%)$ and $27(57.4 \%)$ respectively (Table 2). One student who claimed that the class is utterly unnecessary stated that medical students should study "ethics" per se rather than "medical ethics".

\section{Recognition regarding appropriate semester hours}

In the Student-2000 group, 24 (34.3\%) answered that two semester hours would be suitable. Thirtyone $(44.3 \%)$ chose the option of four semester hours in one year, $9(12.9 \%)$ chose eight semester hours in one year, and 6 students $(8.6 \%)$ responded that even more time would be necessary. On the other hand, 31 (70.5\%) of the Student-2001 group chose four semester hours in a one-year course. Only 4 students (9.1\%) preferred eight semester hours in one year and none responded that even more hours would be necessary (Table 3). The rates for both groups of students claiming that the necessary and sufficient hours for a medical ethics class was two semester hours in a halfyear course, or four semester hours in a year-spanning course $(78.6 \%$ of Student-2000 and $79.6 \%$ of Student2001) were quite similar.

Table 3. Appropriate credit hours for medical ethics course

\begin{tabular}{lcc}
\hline & Student-2000 & Student-2001 \\
\hline 1 credit hour for one term (22.5 hours/half a year) & $24(34.3)$ & $9(20.4)$ \\
1 credit hour for one year (45 hours/year) & $31(44.2)$ & $31(70.5)$ \\
2 credit hours for one year (90 hours/year) & $9(12.9)$ & $4(9.1)$ \\
More credit hours are necessary & $6(8.6)$ & $0(0.0)$ \\
\hline
\end{tabular}

Values are $\mathrm{n}(\%)$. 
Table 4. The appropriate teacher in charge on medical ethics course

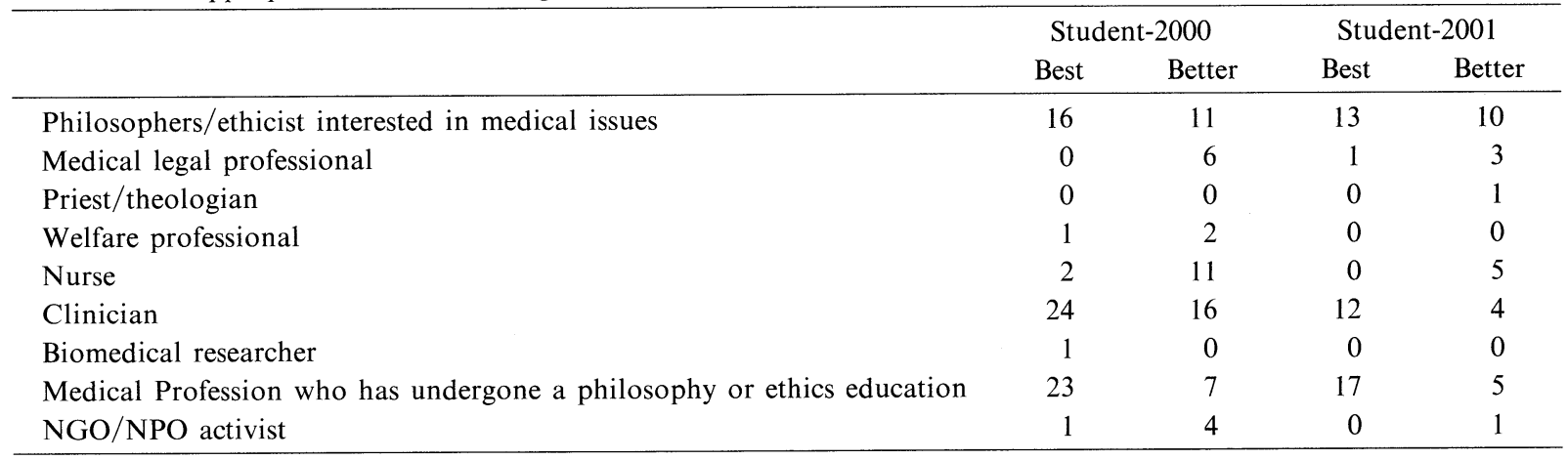

Values are $n$.

Table 5. The class and the National Examination for Physicians (NEP)

\begin{tabular}{lcc}
\hline & Student-2000 & Student-2001 \\
\hline The course should concentrate on the NEP & $3(4.3)$ & $3(7.1)$ \\
Much weight should be devoted to the NEP & $10(12.6)$ & $2(4.8)$ \\
Little weight should be devoted to the NEP & $35(50.7)$ & $22(52.4)$ \\
The NEP should be of no concern & $21(30.4)$ & $15(35.7)$ \\
\hline
\end{tabular}

Values are $\mathrm{n}(\%)$.

\section{Recognition regarding the fitness of various types of teachers in charge}

According to the Student-2000 group, those professionals expected to be appropriate for teaching a course on medical ethics were clinical doctors, whereas the Student-2001 group chose philosophers or ethicists with a vested interest in medicine (Table 4). Characteristic views in common with both sets were that clinical doctors, philosophers or ethicist who were interested in medicine, and medical professionals who had studied philosophy and ethics were expected to be appropriate. Aside from the above-mentioned professionals, some students also felt that nurses and legal professionals specializing in medical concerns were also assumed to be appropriate for teaching medical ethics.

\section{Awareness of the National Examination for Physi- cians and Medical Ethics Class}

Twenty-one $(30.4 \%)$ of the Student-2000 group and $15(35.7 \%)$ of the Student-2001 group expressed feelings that the medical ethics class should be offered separately from classes dealing with the preparation for the NEP, a test in which question are prepared with multiple-choice answers. Thirty-five $(50.7 \%)$ of those in the Student-2000 group and $22(52.4 \%)$ of those in the Student-2001 group stated that the class should not be overly concerned with preparing for the NEP. Three students each $(4.3 \%$ in the Student-2000 group and $6.8 \%$ in the Student-2001 group) would request some sort of link-up between the class and preparations for the NEP (Table 5). The main reason mentioned by many students why the course should not follow the NEP format, was that they could study and prepare to pass the multiple-choice examination by themselves.

\section{Recognition of a suitable method of course evalua- tion}

Fifty-one students (70.5\%) in the Student-2000 group and $32(78.0 \%)$ in the Student-2001 group stated that the suitable method of evaluating student's performance would be an essay test, as opposed to a multiple-choice test (Table 6). Some students who preferred a multiple-choice examination expressed concerns about the possibility that a subjective ethical point of view of some teachers might affect their evaluations of students in the case of an essay exam. However, many students stated that in principle the problems of ethics could not be simplified into a multiple-choice question/answer format. They thought that medical ethics was more than simply a block of knowledge.

Table 6. Suitable form of evaluation examination

\begin{tabular}{lcc}
\hline & Student-2000 & Student-2001 \\
\hline Multiple-choice test & $17(25.0)$ & $9(22.0)$ \\
Essay test & $51(75.0)$ & $32(78.0)$ \\
\hline
\end{tabular}

Values are $\mathrm{n}(\%)$

Table 7. Suitable form of the medical ethics class

\begin{tabular}{lcc}
\hline & Student-2000 & Sudent-2001 \\
\hline Primarily Lectures & $6(8.5)$ & $1(2.5)$ \\
Primarily Discussions & $15(21.1)$ & $11(26.8)$ \\
Lectures + Discussions & $50(70.4)$ & $29(70.7)$ \\
\hline
\end{tabular}

Values are $n(\%)$. 
Table 8. Anticipations for the teacher of medical ethics

\begin{tabular}{lcccc} 
& \multicolumn{2}{c}{$\begin{array}{c}\text { Student-2000 } \\
\text { more important }\end{array}$} & $\begin{array}{c}\text { Student-2001 } \\
\text { most important }\end{array}$ & more important \\
\hline Introductions of actual situations in a clinical setting & 23 & 11 & 11 & 4 \\
Explanations of research and theoretical trends & 1 & 3 & 0 & 1 \\
Instigating arguments and dealing with problems & 13 & 7 & 7 & 4 \\
Scholarship in medicine & 2 & 3 & 0 & 2 \\
Scholarship in medical law & 0 & 3 & 1 & 0 \\
Scholarship in philosophy and ethics & 3 & 1 & 3 & 6 \\
Scholarship in medical policy & 0 & 0 & 5 & 0 \\
Responsive to the opinions of students & 7 & 11 & 1 & 5 \\
Offerings of most appropriate moral judgements & 1 & 1 & 1 & 1 \\
Propper manners and etiquette & 1 & 5 & 1 & 6 \\
Presentation of personal opinions and experiences & 1 & 4 & 13 & 2 \\
Thoughts from divergent perspectives & 15 & 16 & & 7 \\
\hline
\end{tabular}

Values are $n$.

Table 9. Grade in which the medical ethics class should be offered

\begin{tabular}{rcc}
\hline & Student-2000 & Student-2001 \\
\hline Grade 1 & $50(70.4)$ & $35(77.8)$ \\
2 & 1 & 2 \\
3 & 4 & 4 \\
4 & 3 & 0 \\
5 & 6 & 0 \\
6 & 8 & 4 \\
\hline
\end{tabular}

Values are $n(\%)$.

\section{Session styles}

Very few students wanted the traditional "lecture style" format to continue. Yet there were not all that many students who wish to have all sessions focusing on discussions either. Many students seemed to favor sessions consisting of both lectures and discussions.

Fifty of the Student-2000 group (70.4\%) and 29 of the Student-2001 group (70.7\%) expressed preferences for combined sessions (Table 7).

\section{Role anticipation for teachers}

With regard to the preferred teachers' roles, the first choice of the Student-2000 group was "introductions of actual situations and problems in a clinical setting" with "thoughts from a number of different perspectives" gathering the second largest response respectively. With regard to the order of responses for the Student-2001 group, "thoughts from a number of different perspectives" gathered the most responses followed by "introductions of actual situations and problems in a clinical setting," "instigating arguments and dealing with problems," and "responsive to the opinions of students," in this order. Other than the fact that the most desired and the second most desired roles are reversed, both groups of students showed similar tendencies. On the other hand, the anticipations for those involved in medical ethics research and scholarship in medical policies and law, all considered to be closely related to medical ethics, received relatively few responses (Table 8).

\section{When to hold the course}

An overwhelming majority of the students stated that the course should start in the students' first year. Among the Student-2001 group, 35 (77.8\%) selected this response, while others seemed to feel that the course should be offered in more than just one year, in which case many said the third or sixth years would be appropriate (Table 9).

\section{Discussion}

The above is an outline of the results of the survey on students' anticipations and demands for a medical ethics course that was conducted for the first time with the cooperation of students from two different school years. It is not the intention of this study to seek out any statistically significant differences with regard to the responses by the two groups of students. Neither is it fostered by a goal to carry out a multivariate analysis of what factors influence the selection of certain responses. Rather, from the data generated by the survey responses, it aims to understand what medical students may need and, based on those needs, to examine how medical ethics education might best be offered to these students from the points of view of self-examination and constructive criticism. ${ }^{9}$

Neither do we feel that any medical ethics course must necessarily be designed solely with regard to the expressed needs of the students who will be taking the course. Such a course would be "a naturalistic fallacy," which derives what is good from what is desired. ${ }^{10}$ Neither can we place absolute importance on the needs and expectations of the students nor can we afford to totally ignore them. Some previous researches included surveys on students' attitudes. Although the authors asked the students what lecture themes they preferred (issues of brain death and organ transplants, cloning humans, assisted reproduction, or 
dying with dignity), no inquiry into the fundamental nature of these courses was actually executed. Before selecting themes for lectures, this thesis seeks to discover the attitudes and needs of the students from a fundamental viewpoint of course construction as a whole.

While it is impossible to assume that all medical students could possibly share a single opinion, we can assume that their responses may vary widely depending on circumstances such as the university, school year, and the form and nature of the previous courses they have taken. Experience tells us that, as is the case with so many survey responses, there are undeniable differences, depending on the school year, the atmosphere of the classes, students' attitudes toward learning, and whether a teacher can get along with his/her students. As far as this survey is concerned, however, the students from two different school years gave considerably similar responses.

Many of the students who participated in the survey seem to be in favor of starting a medical ethics course from the first year. This probably indicates that they are aware that a lack of detailed knowledge in medicine as a natural science would not prove to be a major obstacle to taking a medical ethics course. It may also indicate that judgments based on natural science alone would be made on a different level from those based on medical ethics. Although some said the course should start in a later year, many of those who made this response wanted the course to be offered in more than one year.

Many medical students do not seem to wish to be given (at least not by a teacher) knowledge that can be answered in yes-or-no questions. As far as the courses offered to underclassmen are concerned, giving students knowledge about mere facts and utilizing those teaching techniques designed to prepare students for taking the NEP are not what today's students are looking for. Rather, they are planning to prepare for the NEP on their own as upperclassmen. It is only a matter of time until medical students become capable of reflexively giving correct answers to $80 \%$ of the yes-or-no questions in the NEP after relying solely on a single drill book containing the necessary detailed explanations. Helping them do so should not be the main role of a medical ethics teacher.

What underclassmen in medical schools really want to know seems to be the reality of a clinical setting, what ethical issues physicians face, what decisions they make, what actions they take with regard to their decisions, and how they can acquire the ability to see things from a number of different perspectives. While these students do want a real grasp of the clinical setting, this is not to imply that they necessarily want to swallow whatever experienced doctors practice or tell them about their own situations. Rather, it seems that they want to review and examine what they are told and what is considered to be "medical ethics".

Clinicians are well versed in the reality of medicine and thus can tell others about their own experiences and the decisions that are actually being made in clinical settings. This, however, can sometimes be extremely close to simple dogmatism. Each clinician cultivates a style or belief from his/her own experiences, experiences that are not always shared by other clinicians. When a clinician is engaged in teaching medical ethics, therefore, he/she is always asked to provide a relative evaluation of his/her own beliefs and experiences and to speak from the perspective of self-examination. Sometimes he/she may face honest questions raised by students or researchers of philosophy or ethics about the practices of clinicians. In such cases a clinician who teaches medical ethics should never consider the immensity of his/her own experience to be absolute or ultimate, he/she should never act authoritatively in any way that might oppress free discussions on medical ethics among his/her students, nor should he/she ever show even the slightest hint of such an attitude. What medical students long for is the dynamics of the discussion itself, not a rapid conclusion.

When a researcher of philosophy or ethics teaches a medical ethics course, on the other hand, he/she must be totally familiar with the reality of medical practice. Knowing the reality of medical practice does not necessarily mean having knowledge about state-of-theart medical technology. Rather, it means knowing what ethical issues medical workers confront everyday, how they deal with these issues, and what issues their patients and their patients' families have to confront. Medical treatment is a social act, and the way medicine is practiced can be deeply influenced by the social situation of the times. It is therefore inevitable for a medical ethics educator to have a firm understanding of medical sociology and politics. The necessity of cooperation between medical workers and researchers in human science and social science cannot be overemphasized.

Teaching general academic knowledge in philosophy and ethics in the narrow sense can only stiffen a medical ethics course and discourage the motivation of students to learn. Since medical ethics is based on philosophy, ethics, sociology and politics, there is little possibility of fruitful discussions without introducing achievements in all of these fields as well. It is therefore necessary to provide medical students with sufficient liberal arts courses, aside from their professional medical curriculum, in order to motivate them to 
actively pursue a fundamental grasp of medical ethics. This would also facilitate an avoidance of isolation of medical students ${ }^{11}$ from students in other courses and to nurture a more humane, sensitive and communicative character.

Students who are weak in communication skills are not hard to find. Many students do not have the sufficient ability to face and take what other people say to them, and are ignorant of their colleagues' perspectives. They are often unable to make reasonable responses with regard to what they have been told, or to carry out meaningful conversations with others. They may, however, manage to utter their own intuitive thoughts to others. The ability today's educators are required to have is not so much passing knowledge on to their students. Rather, and above all else, they must help their students develop their communication skills. Offering their students nothing more than the opportunity to speak freely of their intuitive thoughts in class will only encourage a continuation of the aggressiveness and intolerance that today's professionals tend to show.

The essential task for a medical ethics teacher is to provide a relative evaluation of the opinions and values of each of his/her students, to make sure that these students are fully aware of their own ethical positions, and to urge reviews that include serious self-examination. As the need for working as a team increases, medical staff members may often be confronted with conflicts of interest among team members. In such a situation, team members can often lose sight of their patients as they confront these conflicts. A patient and a medical worker seldom share the exact same values or views of life. If importance is attached to avoid doing any harm to patients, it is inevitable to learn to be more receptive to divergent views and values that other people may have, to be able to accept different values as they are, and to carry out a continuous and thorough consideration at all times. Medical ethics teachers are here to show the way. It seems that a certain number of students are making quite a good point when they chose educators capable of being "responsive to the unique opinions of students" for a role of a medical ethics teacher.

Problems that still remain include that the desired outcomes of medical ethics education remain obscure, undefined and largely untested ${ }^{12}$ and that suitable measures of evaluation have yet to be established. ${ }^{13}$ Further investigations are called for.

\section{Conclusion}

It seems appropriate to remark that the cooperation between clinicians and philosophers and ethicists is a basic necessity for a medical ethics course, that such a course should be offered in an introspective classroom format with lively discussions, and that the professors should maintain an attitude of acceptance in order to ensure the expression of divergent perspectives. These are the triad that needs to be confronted in order to provide a meaningful medical ethics education. We hope that the results of this survey may change the direction for programming a medical ethics curriculum of the future.

\section{References}

1. Akabayashi A, Miyasaka M, Kai I, et al. Survey of medical ethics education in Japanese medical schools. Medical Education (Japan) 1999; 30 : 47-53. (in Japanese)

2. Obayashi M. For bioethics education. Osaka : Medica Publisher, 1999. (in Japanese)

3. Kondo H. For enrichment of death education in schools of medicine - a proposal of cultivation through a tutorial program. Annals of the Japanese Association for Philosophical and Ethical Researches in Medicine 1999; 17: 171-178. (in Japanese)

4. Asai A, Fukui T. Medical education, clinical ethics, and bioethics for medical students and residents. Medical Education (Japan) 1999; 30 : 109-112. (in Japanese)

5. Muraoka K. Use of a case study in medicoethical education for nursing students and nonmedical students. Medical Education (Japan) $2001 ; 32: 83-86$. (in Japanese)

6. Japan Society for Medical Education Working Group of Education of Medical Ethics. The medical ethics education curriculum propose in the undergraduate medical education. Medical Education (Japan) 2001; 32: 3-6. (in Japanese)

7. Akabayashi A, Kai I. Study of 5th-year medical student interest in medical ethics and related factors. Medical Education (Japan) 1999 ; $30: 77$ 82. (in Japanese)

8. Miyasaka M, Yamanouchi H, Dewa K, et al. A questionnaire-survey on attitude for bioethics education of 5th-year medical students of Niigata University. Medical Education (Japan) 2001; 32: 427-432. (in Japanese)

9. Hattori K. National Examination for Physicians and the vector of teaching of philosophy and ethics in medicine. Annals of the Japanese Association for Philosophical and Ethical Researches in Medicine 2001 ; $19: 223-230$. (in Japanese)

10. Moore GE. Principia ethica. Cambridge University Press, 1903.

11. Kent H. Medical, health-science students bring different perspectives to interdisciplinary ethics 
course. Canadian Medical Association Journal 1997, 156: 1317-1318.

12. Myser C. How bioethics is being taught: a critical review. In: Kuhse $H$, Singer $P$ (eds.). A companion to bioethics. Massachusetts :
Blackwell publishers, 1998 : 485-500.

13. Gross ML. Medical ethics education: to what ends? Journal of Evaluation in Clinical Practice $2001 ; 7: 387-397$. 